\title{
Continuous Canopy Shake Mechanical Harvesting Systems 1
}

\section{S.H. Futch and F.M. Roka ${ }^{2}$}

Mechanical harvesting systems harvested more than 17,000 acres of Florida citrus in the 2002-03 season. Two types of mechanical harvesters are being used today: continuous canopy shake and trunk shake systems. Continuous canopy shake systems will be discussed in this article and trunk shake harvesting systems will be discussed in other documents.

Two continuous canopy shake harvesting systems (Figs. 1 and 2) are being used to harvest citrus fruit destined for delivery to juice processing plants. One, commonly referred to as a shake and catch system, is a self-propelled unit that shakes the tree canopy causing the fruit to fall from the tree and onto a catch frame. The second system is a tractor-drawn unit (Fig. 3) that simply shakes fruit to the ground, requiring the fruit to be picked up by a hand crew.

Both systems improve harvesting efficiencies by reducing the amount of labor required to harvest the fruit. Continuous shake and catch systems currently used in Florida citrus are manufactured by Korvan Industries, Inc. of Lynden, Washington, and OXBO

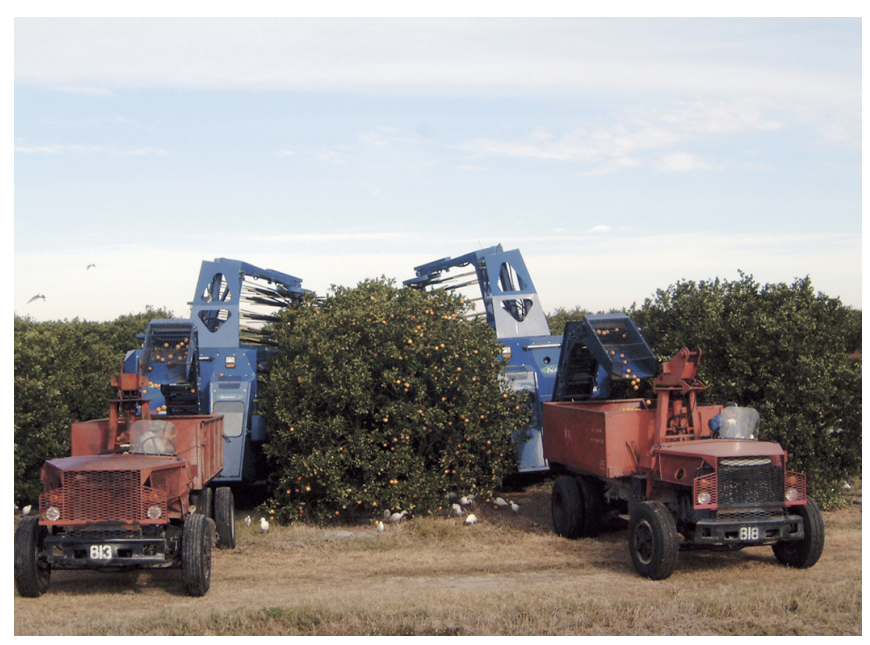

Figure 1. The Korvan self-propelled system.

International Corp. of Clear Lake, Wisconsin. Both manufacturers have extensive knowledge and experience in the development of mechanical harvesting systems for other agricultural crops such as snap beans and blueberries. OXBO also manufactures the tractor-drawn, continuous canopy shake equipment.

Whether self-propelled or tractor-drawn, the core unit of a continuous canopy mechanical harvesting

1. This document is HS1006, one of a series of the Horticultural Sciences Department, Florida Cooperative Extension Service, Institute of Food and Agricultural Sciences, University of Florida. Published March 2005. This research was supported by the Florida Agricultural Experiment Station, and approved for publication as Journal Series No. T-00666. Visit the EDIS Web site at http://edis.ifas.ufl.edu.

2. S.H. Futch, extension agent IV, Horticultural Sciences Department, Citrus REC, Lake Alfred, Florida and F.M. Roka, associate professor, Food and Resource Economics Department, Southwest Florida REC, Immokalee, Florida; Cooperative Extension Service, Institute of Food and Agricultural Sciences, University of Florida, Gainesville, 32611.

The Institute of Food and Agricultural Sciences (IFAS) is an Equal Opportunity Institution authorized to provide research, educational information and other services only to individuals and institutions that function with non-discrimination with respect to race, creed, color, religion, age, disability, sex, sexual orientation, marital status, national origin, political opinions or affiliations. U.S. Department of Agriculture, Cooperative Extension Service, University of Florida, IFAS, Florida A. \& M. University Cooperative Extension Program, and Boards of County Commissioners Cooperating. Larry Arrington, Dean 


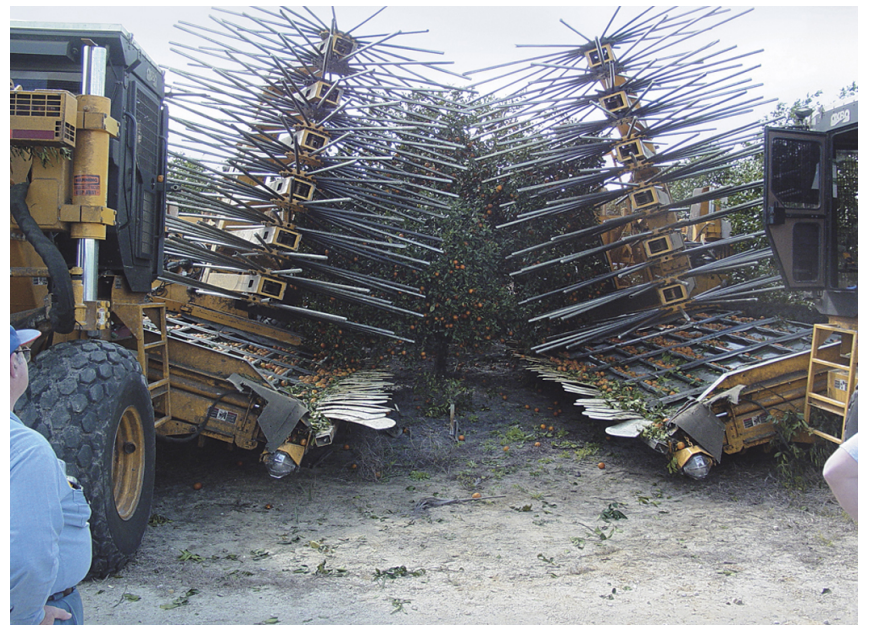

Figure 2. Oxbo's self-propelled system.

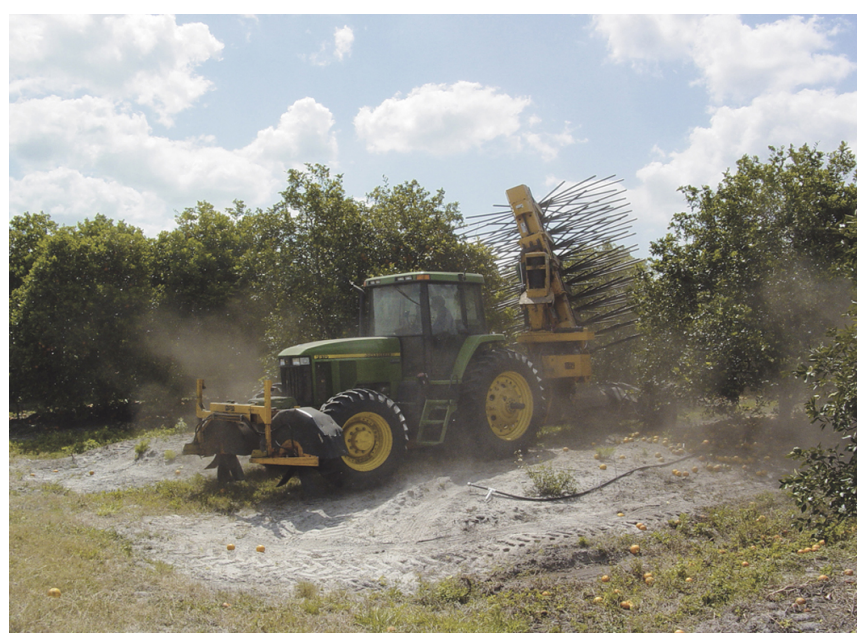

Figure 3. Oxbo's tractor-drawn canopy shaker.

unit consists of a series of whirls stacked horizontally. Each whirl consists of a series of approximately 6-foot-long, 1.5 - to 2-inch-diameter rods mounted to the whirls, which are connected to a central drum. The rods are generally referred to as tines. The tines penetrate into the tree canopy, shaking the canopy horizontally to remove fruit.

The shake frequency of the tines can vary depending on the force needed to remove the fruit. On the OXBO, the operator of the shaker assembly can adjust the angle of the tine penetration to the angle of a hedged tree. The drum is mounted to the controlling unit so that the interaction of the harvesting tines with the canopy begins at 3 feet from the soil surface. The drum, which contains the whirls, can be elevated up to 18 feet above the soil surface. During one pass, the drum can harvest up to 18 feet of canopy height. Hedged trees insure uniformity of tree shape and allow for maximum tine penetration into the tree canopy, thereby increasing fruit removal. To minimize fruit splitting from impact with the ground or catch frame, trees should be topped to a maximum of 16 to 18 feet.

Self-propelled harvesting units work in pairs, one unit for each side of the tree. Each unit has leveling hydraulics, which allow it to work effectively in bedded groves. The paired units travel down the tree row at ground speeds that can vary from 0.5 to 1.3 miles per hour, thus allowing 200 to 400 trees per hour to be harvested. Each unit catches and separates the fruit from leaves and stems, reducing the amount of trash delivered to the processing plant. Fruit can be conveyed directly to a goat-type truck, or up to 60 boxes can be temporarily stored on the OXBO harvester's deck to allow for continuous operation. The goat-type trucks are similar to a conventional harvesting goat but slightly larger with a capacity of between 130 and 150 boxes. These units transport the fruit to semitrailers, which deliver the fruit to the processing plants.

For maximum efficiency, the self-propelled shake and catch units are best suited for groves with uniform tree canopy size. Canopy uniformity can be facilitated by hedging and topping. Trunk alignment in the row, clear trunk height of 18 inches to the first branches, and long tree row length improve harvesting efficiency. Skirting height of 30 inches above the ground allows for the catch frame to easily travel under the tree canopy, minimizing lower limb damage and maximizing fruit recovery. Tree topping height should not exceed 16 to 18 feet and trees should have a canopy width from the tree trunk to the outer canopy of 6.5 to 8 feet.

Some hand labor may be required to glean any fruit remaining in the tree or to retrieve fallen fruit that missed the catch frame. Under grove conditions outlined above, continuous shake and catch systems typically deliver 90 to $95 \%$ of the available fruit to the semitrailer. With gleaning crews, total fruit recovery approaches $98 \%$. In cases where fruit prices are low, hand labor to glean fruit may not be economical.

A self-propelled continuous canopy shake and catch system uses a crew of six workers - 2 harvester operators and 4 goat drivers. Overall, harvest labor 
productivity improves from 5 to 10 times over a hand crew, depending on grove conditions and equipment downtime.

For groves that lack tree size uniformity and have not been skirted, the tractor-drawn continuous canopy shaker provides an option with greater flexibility for the adoption of mechanical harvesting systems. This tractor-drawn system works in a similar fashion to the canopy shake and catch units but without the catch frame. Tines mounted in the whirl remove the fruit from the tree by a horizontal shaking action, allowing the fruit to fall to the ground. As with the self-propelled unit, the operator can adjust the tilt and elevation of the drum that contains the series of stacked whirls. Harvesting area is limited to the height of 18 feet. With an experienced operator and in trees less than 18 feet in height, $95 \%$ of the crop can be removed from the tree.

The tractor-drawn canopy shake system must work in conjunction with a hand crew to gather fruit shaken off by the harvesting unit. The harvester can travel between one-half and one mile per hour and have the capacity to harvest between 100 and 200 trees per hour. The efficiency of this harvester is influenced by the size of the pickup crew. Typically, a harvester shakes only the number of trees that will provide the fruit that can be picked up within a day.

The pick up crew gathers fruit into 8- or 10-box tubs, which are then loaded into conventional high lift trucks or goats. Since hand crews glean most of the remaining tree fruit, the tractor-drawn canopy shaker system in conjunction with hand labor delivers up to 99\% of the available crop. When the tractor-drawn canopy shaker is used, labor harvest efficiencies as compared to standard hand harvesting are improved by at least twofold.

As with the shake and catch systems, trees should be hedged with a canopy width from the trunk of the tree to the outer skirt of no more than 8 feet. Trees should be topped to a height of no more than 18 feet. Multi-stemmed tree trunks or low hanging branches do not decrease harvesting efficiency as significantly as they do when the catch frame systems are utilized.
Harvesting and roadside costs in the 2003-04 season for continuous canopy shake systems can range from $\$ 1.00$ to $\$ 1.75$ per weight box. The lower cost range reflects well-prepared, high-yielding trees that are harvested with a catch frame, and does not include the cost of a gleaning crew to collect non-harvested fruit. The cost per box of the tractor-drawn system typically is higher due to the additional labor requirements to gather the fruit from the ground. Actual harvesting costs will depend on specific grove conditions and gleaning requirements of the grower.

Higher-yielding blocks should enjoy a lower per-box cost of mechanical harvesting. Larger blocks or tracts in close proximity should command a lower price, since the harvesting equipment can work more efficiently for a longer sustained period of time. Whatever the price of a mechanical system, the relative comparison a grower needs to consider is the price a hand crew would charge to pick and roadside the same volume of fruit.

For the Florida citrus grower to remain competitive in a global environment, all options that reduce the harvesting costs must be considered. Mechanical harvesting for processed citrus fruit is a viable option to lower harvesting cost. Ongoing research conducted by the Florida Department of Citrus, the University of Florida, and private companies show that the above systems can reduce harvesting costs by 20 to 40 cents per box. Additionally, studies that have been conducted for multiple years have shown no adverse effects in tree health, productivity, or tree longevity where these systems have been used. 
Table 1. Canopy Shake Mechanical Harvester Manufacturers and Contractors

\begin{tabular}{|lccc|}
\hline \hline \multicolumn{1}{l}{ Manufacturers } & City & Contact Name & Phone Number \\
Korvan Industries, Inc. & Lynden, WA & Scott Korthuis & $360-815-1548$ \\
OXBO International Corp. & Clear Lake, WI & Gary Stich & $585-548-2665$ \\
Contract Harvestors & & \\
Everglades Harvesting \& Hauling, Inc. & Self-propelled Continuous Canopy Shake & \\
Rectangle Harvesting, LLC & LaBelle, FL & Paul Meador & $863-675-8500$ \\
Sam Adams & Avon Park, FL & Gale Murdock & $863-453-3142$ \\
T \& S Harvesting & Felda, FL & Sam Adams & $863-673-0404$ \\
& Felda, FL & Tom Visser & $863-675-4046$ \\
Mutual Harvesting, Inc. & Tractor-pulled Continuous Canopy Shake & \\
\hline \hline
\end{tabular}

